\title{
Analysis on the Self-Built Characteristic Database and Intellectual Property Protection of University Library
}

\author{
Wenbin Zheng ${ }^{1, *}$ Na Zhang ${ }^{1}$
}

${ }^{1}$ College of Information and Communication, National University of Defense Technology, Xi'an, Shaanxi 710106, China *Corresponding author. Email: 359531099@qq.com

\begin{abstract}
With the rapid development of information technology, digital library provides readers with convenient and fast information services. In order to meet the needs of teaching and research and personalized information of readers better, each university library is building its own characteristic database, which makes the risk of intellectual property increasingly prominent. This paper analyzes the relationship between the self-built characteristic database and intellectual property, the intellectual property problems of the characteristic database in the process of construction and service, and how to protect the intellectual property, avoid the risk of infringement, balance the relationship between the library and the copyright owner, and build the intellectual property system of the self-built characteristic database of university library.
\end{abstract}

\section{Keywords: university library, self-built characteristic database, intellectual property}

\section{INTRODUCTION}

The university library is a university literature information resource center. As an important position for the construction and preservation of information resources and the provision of information services, the university library takes advantage of the characteristic resources of the collection to build a characteristic database to better serve the teaching and scientific research and satisfy the reader's different information needs are an important part of information resource construction and personalized services in college libraries. However, at present, university libraries are prone to intellectual property rights infringement in the process of collecting, constructing and serving special database resources. Intellectual property rights restrict the development of characteristic databases. Only by solving copyright issues can we avoid intellectual property risks, promote the construction and development of self-built characteristic databases, and maximize the benefits of resources.

II. THE RELATIONSHIP BETWEEN SELF-BUILT CHARACTERISTIC DATABASE AND INTELLECTUAL PROPERTY

\section{A. Self-built characteristic database}

In December 2015, the Ministry of Education of our country issued the newly revised "Regulations of General College Libraries" Article 23 stipulates: libraries should coordinate paper resources, digital resources and other carrier resources in the construction of document information resources; maintain important documents and special resources integrity and continuity; pay attention to the collection of teaching and scientific research materials and achievements of the university and various types of carriers related to the university; search and accept social donations; form a document information resource system with the characteristics of the university. University libraries carry out characteristic database construction according to the purpose and characteristics of running a school, just like our library's self-built communication technology book database and foreign science and technology journal database are all characteristic database resources.

The characteristic database is for a certain subject or topic, relying on the advantages of library collection resources and its own resource construction in colleges and universities, to collect, process and digitize resources according to certain rules, making it available for users at different stages according to their needs Integral and shared data collection for use. Compared with the traditional works protected by intellectual property rights, the characteristic database has the characteristics of information intensiveness, system sequence, individual accessibility, system openness, convenient retrieval, easy replication and content characterization. The characteristic database is divided into the index database and the full-text database. The author discusses the issue of self-built full-text characteristic database and intellectual property protection. 


\section{B. Intellectual property}

The intellectual property protection system is an important legal system that promotes cultural prosperity and technological innovation, and is also an important manifestation of the country's soft power.

At the opening ceremony of the Boao Forum for Asia Annual Conference on April 10, 2018, President $\mathrm{Xi}$ Jinping pointed out: Strengthening the protection of intellectual property rights is the most important part of improving the property rights protection system, and also the biggest incentive to improve China's economic competitiveness. These words once again conveyed China's firm stance and clear attitude to strictly protect intellectual property according to law.

The library's job is to use books and literature and various types of information resources to provide services for teaching, research and readers, whether in the construction of resources or in the process of serving readers, intellectual property legal issues will be involved. Intellectual property rights are a huge system, and the content involves multiple fields, including copyright, patent rights, trademark rights, new plant variety rights, and integrated circuit layout design exclusive rights. Judging from the provisions of various intellectual property rights, the main work related to library work is copyright, and this research also focuses on copyright.

According to the provisions of the Copyright Law of our country, the so-called copyright refers to the exclusive rights that natural persons, legal persons or other organizations have for works in the field of literature, art and science, including personal rights and property rights, which mainly include: the right to publish, sign, The right to modify, protect the integrity of the work, the right to copy, the right to rent, the right to exhibit, the right to perform, the right to distribute the information, the right to broadcast the information, the right to show, the right to film, the right to translate, the right to adapt, the right to compile and other rights that should be enjoyed by the copyright owner right. Judging from the laws and regulations that have been promulgated and implemented, the legal basis for the protection of copyright in China is mainly the "Copyright Law of the People's Republic of China" and its implementation regulations, "Computer Software Protection Regulations", "Copyright Collective Management Regulations", and "Information Network Communication Protection" The Regulations and the Supreme People's Court "Interpretation on Several Issues Concerning the Application of Law in the Trial of Copyright Civil Dispute Cases" and "Provisions on Several Issues Concerning the Application of Law in the Trial of Civil Dispute Cases Infringing on the Right to Disseminate Information on the Internet" Two judicial interpretations. In addition, the international conventions on intellectual property rights to which
China has acceded should also comply with the provisions on copyright.

\section{Relationship between self-built characteristic database and intellectual property}

There is a contradictory and unified relationship between the self-built characteristic database of university libraries and intellectual property rights. The construction of the characteristic database is mainly to digitize the paper special documents in the collection, download and use of the relevant characteristic resources of the existing commercial database, etc., but only changes the carrier of the original work, and the content has not been changed. It will infringe the copyright of the original work, cause unnecessary intellectual property disputes, restrict the library's use of information resources, hinder the construction and development of the characteristic database, so the two are contradictory; the construction of the characteristic database consumes a lot of The human, material and financial resources, especially the collection of resources, digital processing, selection of description fields, determination of description rules, and editing of description content are the intellectual achievements of database builders. They are original and belong to compilation works.so they are protected by intellectual property laws. The Intellectual Property Law protects the rational use of original characteristic resources, protects database construction from infringement risks, and protects the intellectual property rights of the characteristic database as a whole. The perfection of property rights laws, so the two are unified. Therefore, libraries need to objectively analyze the relationship between the two, and then seek a balance point to ensure the synergy and sustainability of the development of the two, so that the library self-built characteristic database is constructed according to law, and a virtuous cycle of knowledge protection and utilization.

\section{INTELLECTUAL PROPERTY ISSUES IN THE COLLECTION AND CONSTRUCTION OF CHARACTERISTIC DATABASE RESOURCES}

The resource collection of characteristic database construction mainly includes the following aspects:

- Digitization of relevant characteristic paper documents in the collection;

- Works of teachers and students in the school, such as teachers' works, papers, planned assignments and handouts, and students' degree papers;

- Collection of relevant materials from the purchased commercial database. 


\section{A. Digitization of collection-specific paper documents may infringe the copyright of the original work}

The digitization of paper documents related to collections in university libraries is mainly achieved by using information technology to convert the paper form of documents into digital form. The essence is the reproduction of the original document resources after changing the carrier. It does not possess the creativity in the sense of copyright and belongs to the act of reproduction. Digitization of paper documents may infringe the rights of reproduction and online transmission of works.

When protecting the author's copyright, the Intellectual Property Law also made reasonable restrictions on the exercise of their rights to promote the dissemination of knowledge. Fair use refers to the use of a work by someone other than the copyright owner under certain circumstances, that is, exercising the rights that the copyright owner has the right to exercise in accordance with the law. It may not be paid without the permission of the copyright owner, but the name of the author should be indicated. The title of the work, and shall not infringe upon the other rights of the copyright owner. Article 22 of the "Copyright Law" of our country lists the scope and specific methods of reasonable use, of which paragraph 6 provides: "For school classroom teaching or scientific research, translate or copy a small amount of published works for teaching or research personnel, but No publication or distribution ". Article 7 of the "Regulations on the Protection of the Right to Disseminate Information Networks" provides: "Libraries, archives, memorials, museums, art galleries, etc. may provide service objects in the building of the library through the information network without the permission of the copyright owner. Legally published digital works and works that need to be copied in digital form for display or preservation according to law shall not be paid, but they shall not directly or indirectly obtain economic benefits.

With the provisions of reasonable use, it provides convenience for the collection of characteristic database resources. As long as it is used reasonably and grasped well, there will be no risk of infringement. However, the following points should be noted when grasping the fair use regulations:

- Fair use is only for "published works" and "noncommercial use". If digitizing unpublished works or directly or indirectly obtaining benefits, fair use will not apply. Regulations raise intellectual property issues;

- Reasonable use of works shall not infringe the personal rights of the copyright holders such as the right to sign, modify and protect the integrity of works; "Service object in the house" should be understood as the service object of the university library, not limited to the building in the building, so that the characteristic database is not restricted by time and space, and provides information services for readers of the library. The maximum utilization benefit of the characteristic database.

\section{B. Copyright risk in digitizing works of teachers and students on campus}

The characteristic database is based on a certain subject or a certain research field of universities, collects and constructs relevant data, and provides information services for it. The monographs, thesis, scientific research achievements, assignments and lecture notes of teachers and students in the university are the key points that distinguish the characteristic database from the databases built by other universities and reflect the characteristics. When digitizing these works, if you do not obtain authorization, you will infringe the copyright holder's reproduction rights, publishing rights and online communication rights. Because such works are mostly unpublished works, the scope of reasonable use of copyright law does not apply.

For the scientific research achievements of university teachers, some belong to the legal person works of the university, that is, the copyright belongs to the university where the copyright belongs; and some belong to the teacher's professional work. For this part of the document resources, the university library can use it reasonably. For other works, you can obtain the authorization of the copyright owner through the authorized use license to fundamentally solve the intellectual property problem of the characteristic database construction.

\section{Intellectual property risk when collecting relevant resources from purchased commercial databases}

In order to build a digital library and meet the teaching and scientific research needs of teachers and students in colleges and universities, the library will purchase a certain amount of digital resources closely related to teaching and scientific research. Commercial databases also have their own intellectual property rights, usually set to prohibit batch download, continuous download, abuse of database resources for commercial or profitable purposes to protect their rights.

"The Berne Convention for the Protection of Literary and Artistic Works" defines downloading as a copying act. Downloading the database's documentation must not only control the reasonable scope of use, but also limit the number of downloads. In the process of providing database literature downloads, if there is no clear regulation on the number of downloads and the scope of use, a large number of 
illegal downloads and violations of intellectual property rights will occur.

\section{INTELLECTUAL PROPERTY PROTECTION IN THE PROCESS OF CHARACTERISTIC DATABASE SERVICE}

In the process of service of characteristic database, the self-built characteristic database for intellectual property protection is authoritative and original. It belongs to the compilation work, and its copyright belongs to the database builder and is protected by the intellectual property law. When providing information services, we should do a good job in double protection, not only protecting the whole database, but also protecting the intellectual property rights of the works in the database.

\section{A. Strengthening education management to achieve legal use}

The publicity and education of intellectual property laws and regulations shall be carried out through the production of user manuals and lectures on intellectual property, and the publicity shall be made in the form of "copyright announcement" or "instructions for the use of electronic resources", so as to let the readers know the importance of intellectual property protection and relevant measures, use the information resources of self-built characteristic databases within the legal and reasonable scope, and avoid infringement.

\section{B. Using technology to protect the intellectual property of characteristic database}

Using technical measures to protect the characteristic database is an important means to avoid malicious access, batch download, abuse of database resources, and protect the intellectual property rights of the characteristic database. On the one hand, we can learn from the protection measures of commercial database, for example, the commonly used technology is access control technology, which has two modes, namely, "IP authentication" which only provides services for the devices in the IP address segment of colleges and universities, and "ID authentication" which requires users to enter "user name + password" to $\log$ in. On the other hand, we can set up digital watermarking technology, digital signature technology, etc. to set a threshold for the piracy of works, to avoid resource flooding or malicious use; set up a firewall to effectively isolate the internal network and the external network, to prevent the external personnel from illegally accessing the characteristic database resources, etc. In addition, the library can also set different levels of reading and downloading authority for the whole database or part of data resources according to the characteristics of confidentiality and utility of characteristic database data, so as to maximize the protection of database intellectual property rights.

\section{Paying attention to intellectual property protection of tacit knowledge in characteristic databases}

Tacit knowledge refers to non-coded knowledge that is difficult to express, record and transfer based on the accumulation of long-term life and work practices, including ideas, skills, thinking and know-how. The construction of the characteristic database of university libraries embodies the collective wisdom of librarians and libraries. Among them, the selection of specific bibliographic fields, the content of bibliographic editing, and the combination of data sequence are all manifestations of long-term accumulated experience and skills, which are tacit knowledge.

Tacit knowledge is a potential intellectual capital of libraries that is often more valuable than explicit knowledge. On the one hand, in the process of database construction and service, attention should be paid to the protection of invisible knowledge of the library to prevent infringement by other libraries and affect the core competitiveness of the library; on the other hand, an effective incentive evaluation mechanism and Sharing mechanism, because some tacit knowledge is mastered by the librarians themselves. Through the incentive assessment and sharing mechanism, the librarians are encouraged to dedicate their knowledge to the library, realizing a virtuous cycle of tacit knowledge sharing, so that other librarians can also grasp important tacit knowledge and can alleviate and eliminate the negative impact of the loss of key librarians on library development and innovation. It can help libraries gather tacit knowledge and form the collective spiritual wealth of libraries.

The Intellectual Property Law grants creators rights and protects their rights and interests, and its purpose is to encourage the creation of knowledge. The characteristic database construction is to improve the efficiency of using knowledge. The goals of the two are the same, both are to promote the development of human civilization, but the way of realization is different. One is legal means and the other is technical means. Only under the premise of correctly understanding the law can the construction of characteristic databases be carried out smoothly.

University libraries should strengthen the awareness of intellectual property protection, strengthen the training of librarians on intellectual property knowledge, and try to avoid infringement during the construction of characteristic databases, so that database construction can be carried out in accordance with the law; Understand the importance of intellectual property protection and related program measures, and rationally use the information resources of self-built characteristic databases according to law. University libraries should continue to pay attention to the development of laws and regulations related to intellectual property rights at home and abroad, collect 
relevant cases of intellectual property protection at home and abroad, draw lessons from them, and formulate and develop the library based on the actual characteristics of the library's characteristics and service groups. The matching intellectual property rights protection rules and regulations shall have a legal basis in the event of infringement of characteristic databases. Eventually, it will not only protect the rights and interests of authors, but also actively promote the construction and service of unique databases.

\section{CONCLUSION}

University libraries should establish awareness of intellectual property protection, strengthen the learning of intellectual property-related legal knowledge, actively draw on relevant experience and practices, establish an intellectual property protection system suitable for the resource construction and services of the library, and implement self-built characteristic databases according to law and service In order to meet the personalized information needs of readers and promote the spread and use of knowledge. At the same time, it also provides specific cases for the improvement and development of the intellectual property system to achieve benign interaction and common development.

\section{References}

[1] Xue Jian. Copyright problems and countermeasures in the construction of library characteristic database [J]. Science and Technology Information Development and Economy, 2012, (1): 3-5

[2] Cao Zhimei. Self-built characteristic database of university library to reasonably avoid the risk of infringement risk [J]. Information Exploration, 2016 (3): 59-61.

[3] Yan Lang. Analysis on Copyright Issues of Self-built Characteristic Database of University Library [J]. Journal of Zhengzhou Railway Vocational and Technical College, 2008 (3): $87-88$.

[4] Chang E. On the Information Resource Construction and Intellectual Property Protection of University Digital Libraries [J] 2008 .

[5] Liu Jigang. Copyright Analysis of Self-built Characteristic Database of University Library [J]. Library research work. 2017, 1 (1): 52-57.

[6] Tong Tianle. On the intellectual property rights infringement risk of library digital resource services $[\mathrm{J}]$. Modern Information, 2009, 28 (8): 93-95. 